\title{
Using Cover Crops to Manage Arthropods on Truck Farms
}

\author{
Robert L. Bugg \\ University of California, Information Group, Sustainable Agriculture Research and Education Program, Davis, CA 95616
}

\section{Biological and cultural control: Cover crops as nexus}

Cover crops represent an important nexus in sustainable vegetable culture; they affect many aspects of production, including pest management. Many of the arthropod pests that attack vegetable crops are themselves attacked by natural enemies, including predatory and parasitic arthropods. If cover crops are used to reduce pest dispersal, colonization, or reproduction on vegetable crops, this is usually termed cultural control. This method involves: 1) maintenance of the cover crop as a sink for various pests, 2) use of cover crops to confuse pests visually or olfactorally and thus reduce their colonization of vegetable crops, 3) cover crops having nutritional effects on host plants, and 4) cover crops causing microclimatic changes that reduce pest success. However, if the aim of the methodology is to enhance performance of natural enemies, strict constructionists consider this an aspect of biological control. At times, cultural and biological controls may

The preparation of this manuscript was funded in part by the Wallace Genetic Fund, Inc. operate simultaneously [see reviews by Altieri and Letourneau (1982) and Andow (1988)].

The dynamics of arthropod dispersal to and from cover and vegetable crops are still poorly documented (see Kennedy and Margolies, 1985) and management options to enhance cultural and biological control only crudely formulated. The present article focuses mainly on cover crops as sinks and sources of pests, and reviews relevant literature, yet also entails considerable speculation.

\section{Yin/yang (sink/source) dynamics}

In Chinese philosophy, religion, and medicine, we encounter the notion of polarity, of the twin principles of yin and yang, variously (and sometimes merely metaphorically) manifested as feminine and masculine, dark and light, earthly and divine, receptive and creative, rest and movement, or sink and source (Cleary, 1986). These dual principles are believed to interact throughout the universe and at all scales, leading to configurations of opposition and complementarity. The dynamics are complex: sink and source can interpenetrate and actually become one another. This may be heady stuff for horticultural\&s, yet 
yin-yang dynamics are apparent in diversified truck farms throughout the world. At the grossest level, arthropods may colonize a crop during a period of suitability, and disperse when maturation, senescence, harvest, tillage, or other phenomena render that crop unsuitable. Thus, a sink can become a source. Dispersal may take these arthropods to associated crops of greater or lesser suitability than the crop that was formerly occupied. This can occur with either pests or their natural enemies. Populations of certain pest or beneficial arthropods may build up in cover crops and disperse to vegetable crops, particularly when the former mature, die, are stressed by drought, or are mowed, tilled, or treated with herbicides. The idea of trap or diversionary crops may be applicable to cover crops: it centers on keeping these attractive, that is, maintaining them as sinks for pests during periods when the target crops would otherwise be prone to attack (Fleischer and Gaylor, 1987; Hokkanen, 1991).

\section{Complements and supplements}

At subtler levels, crops may provide alternate foods, some that complement and some that supplement foods provided by other crops. For example, ichneumonid wasps may feed as adults on nectar provided by bell bean (Vicia faba L.) (Bugg et al., 1989) but as larvae may parasitize caterpillars that infest various vegetable crops. Thus, the vegetables and the bell beans can provide dissimilar foods that complement one another. Various Apiaceae such as carrot (Daucus carota L.) (Hirose, 1966) and sweet fennel (Foeniculum vulgare Miller var. dulce Battandier $\&$ Trabut) (Maingay et al., 1991) also attract wide ranges of nectarivorous parasitic wasps that attack pests of vegetables. Such Apiaceae are now included in commercially available "insectary cover crop" seed mixes (e.g., those sold by Germain Seed Co.; Harmony Farm Supply, Sebastopol, Calif.; Peaceful Valley Farm Supply, Grass Valley, Calif.). Certain pests also use several of these nectar sources.

If two crops provide similar foods, such as corn and tomato providing different kinds of caterpillars for ichneumonid larvae to parasitize, these resources are said to supplement one another. Even so-called supplementary resources may complement one another in the sense of being available in a temporal sequence. For example, during late winter and early spring, rye (Secale cereale L.) sustains bird-cherry oat aphid Rhopalosiphum padi L.), whereas hairy vetch (Vicia villosa Roth) later harbors abundant pea aphid (Acyrthosiphon pisum Harris). These serve as prey to various lady beetles (Coccinellidae), and the patterns of aphid abundance are reflected in lady beetle attendance and reproduction on these plants, whether grown in monocultures (Bugg et al., 1990a) or in mixtures (Bugg et al., 1991). Bird cherry-oat aphid also serves as host to a parasitic aphidiid wasp (Diaeretiella rapae M'Intosh) that can also attack cabbage aphid (Brevicoryne brassicae L.) and green peach aphid (Myzus persicae Sulzer), both important pests of vegetable crops (Marsh, 1979). The practical implications for manipulating D. rapae remain to be seen. Coarse- vs. fine-grained interspersion of such sequential food sources might be expected to affect dispersal of predators and parasites and their movement into nearby vegetable crops, but this has yet to be explored experimentally.

A distinction is also made between foods that sustain reproduction (essential foods) and those that do not. For example, in lieu of aphids, convergent lady beetle (Hippodamia convergens Guerin-Meneville) can subsist on pollen or nectar (Hagen, 1974) or flower thrips (Thysanoptera: Thripidae) (Bugg et al., 1990); these foods permit fat accumulation, but not egg development (Hagen, 1974). There are also foods of intermediate value. For example, the pink lady beetle (Coleomegilla maculuta Degeer), an important generalist predator in vegetable crops (Groden et al., 1990), can reproduce on a diet of pollen alone (Hodek et al., 1978; Smith, 1960), but the addition of pea aphid to the diet increases the proportionof larvae that attain adulthood (Smith, 1960). It is not clear to what extent predators may be diverted by foods that do not sustain reproduction.

\section{Sink out of sync? Don't supplement those complementary refreshments!}

Although they may provide natural enemies with important comple- mentary and supplementary foods, cover crops can remain sinks for natural enemies throughout the growing season. Generalist predators may be important in the biological control of insects that attack warmseason vegetable crops (Bugg and Wilson, 1989; Bugg et al., 1991). Such predators can reproduce or at least subsist on nectar, pollen, spider mites (Acari: Tetranychidae), thrips (Thysanoptera), or aphids (Homoptera: Aphididae), and thus be in place before the arrival of key pests (Ehler and Miller, 1978; Bisabri-Ershadi and Ehler, 1981; Tamaki, 1981; Gonzalez et al., 1982).

Cover crops can help sustain generalist predators; however, complications may occur. Cabbages grown in combination with perennial legumes (living mulches) do not necessarily feature higher densities of beneficial insects, as shown in northern New York (Andow et al., 1986).

In California, common knotweed (Polygonum aviculare L.) is often tolerated and serves as a de facto cover crop in permanent-bed truckfarming systems and in heavily trafficked roadside areas adjoining vegetable fields. Bugg et al. (1987) used this nectar-bearing, summerannual weed in efforts to enhance performance of bigeyed bugs (Geocoris punctipes Say, G. pallens Stål, and G. atricolor Montandon) on adjoining vegetable and field crops. The weed produces flowers indeterminately and provides nectar to Geocoris spp. and other generalist predators; the nectar presumably serves as a complement to arthropod prey. However, from early spring until the plant dies in late autumn, it also harbors abundant supplementary foods [thrips, spider mites, a psyllid (Aphalara curta Caldwell), and an aphid (Aphis avicularis Hille Ris Lambers); the latter two are host-specific]. Thus, normal phenology of common knotweed does not appear to prompt dispersal of predators to adjoining warm-season crops, such as bell pepper. However, in fall, adjacent plantings of radish (Raphunus sativus L.) might benefit from increased densities of Geocoris spp. as the insects disperse from senescing common knotweed.

Analogous problems may have occurred when flowering buckwheat (Fagopyrum esculentum Moench) was used in efforts to enhance biological control by spiders in vegetable crops: spiders may have been diverted from attacking pests by readily available alternative prey: insects attracted to the flowers (Riechert and Bishop, 1990).

\section{A source perforce}

The relationships are quite different if summer vegetables are relay-intercropped with cool-season cover crops. The latter could be managed with reduced tillage as "dying mulches" that senesce, die, or are partly suppressed because of heat and water stress when warm weather begins, as has been shown in southern Georgia (Bugg et al. 1990a, 1991). High densities of a bigeyed bug, G. punctipes, have been observed during late spring on arrowleaf clover (Trifolium vesiculosum Savi), berseem clover (T. alexandrium L.), and subterranean clover ( $T$. subterraneum L.) (Bugg et al., 1990a). On cool-season cover crops, G. punctipes probably subsists on spider mites, Collembola, thrips, aphids, tarnished plant bug (Lygus lineolaris Palisot de Beauvois), other arthropods, and, in the case of common vetch (V. sativa L.) and its close relatives, on extra-floral nectar. As warm weather increases with the onset of summer, the cover crops senesce and provide progressively less-suitable habitat. Under such conditions, G. punctipes may disperse to adjoining truck crops. In a replicated trial, Bugg et al. (1991) used seven different cool-season cover crops and a weedy fallow in relayintercropping schemes with spring-sown cantaloupe. Cover-crop regime significantly affected densities of bigeyed bug amid cover crops, on or near cantaloupe plants, and on or near sentinel egg masses of fall armyworm (Spodoptera frugiperda Hübner) pinned to cantaloupe leaves. For all indices of predator abundance and efficiency, mean densities were highest for the plots of subterranean clover. Numbers of bigeyed bug per sentinel egg mass were significantly greater for the subterranean clover regime than for rye, crimson clover, and a polyculture of six cover crops but were not significantly greater than for 'Vantage' vetch $(V$. sativa $\times V$. cordata Wulf) or the weedy fallow control plots. Rye showed particularly low densities of bigeyed bug. During periods of declining densities amid subterranean clover and 
other cover crops, G. punctipes tended to be particularly abundant amid adjoining cantaloupe plants and on sentinel egg masses. This pattern suggests that the predator dispersed from dying cover crops to the adjoining cantaloupe plants, and that predation was thereby enhanced. Thus, strips of late-maturing legumes like berseem clover, arrowleaf clover, and certain subterranean clovers could serve as insectaries, because they can harbor relatively high densities of $G$. punctipes (Bugg et al., 1990a). Subterranean clovers appear particularly promising because they harbor relatively few tarnished plant bug, which could damage adjoining field, row, or orchard crops (Bugg et al., 1990b). Subterranean clovers have also successfully suppressed weeds when relay-intercropped with various vegetable crops. However, late-maturing subterranean clovers and other legumes may compete with truck crops for water or nutrients. Innovative design and management of relayintercropping schemes could help resolve this conflict. "Insectary strips" of late-maturing clovers could also be established along field margins or irrigation lines.

Results of Meagher and Meyer (1990) in North Carolina suggest that cover crops dominated by a single species may lead to wholesale dispersal of pests to cash crops. Where the herbicide Simizine is applied to the understory vegetation of peach orchards, narrowleaf vetch [V. sativa L. ssp. nigra (L.) Erh.] tends to dominate the undertstories, and infestations of spider mites tend to be exacerbated. The authors indicate that the lack of other, later-maturing hosts may predispose spider mites to migrate into trees. Analogous problems could be expected with vegetable crops associated with some kinds of cover crops used in monoculture.

When green manure crops are plowed down, the decomposing residues may be colonized by seed corn maggot (Delia platura Meigen). Vegetable seedlings sown thereafter may also be attacked directly by the maggots, or oviposited on by the adult fly (Davidson and Lyon, 1987; Metcalf et al., 1962). In this situation the decomposing residue acts as a sink, then a source, as scavenging maggots transfer to the seedlings. Gold, wet weather prolongs decomposition of cover crop residue and retards growth by the seedlings, increasing the damage caused by this pest. In lieu of seed treatment, delayed or repeated seeding of the cash crop may be necessary to deal with these problems.

In Florida, wireworms (Conoderus rudis Brown, C. amplicollis Gyllenhal, and Melanotus communis Gyllenhal) may be exacerbated by summer cover crops of sudangrass (Sorgum bicolor L. Moench) preceding potato. However, delaying cover crop seeding until July apparently can decrease the colonization by avoiding peak flight periods by the female beetles; subsequent problems for potato are therefore reduced (Jansson and Lecrone, 1991). Thus, avoiding creating a sink can help avoid creating a source.

\section{Management options}

Three key concepts in host-plant resistance to arthropods are: 1) escape (avoidance of pest problems due to intervarietal phenological differences); 2) nonpreference (host-plant variety does not attract pests); and 3) antibiosis (host-plant variety reduces viability of pests). The truck farmer who manages cover crops in order to reduce pest problems is working with these concepts, but at a higher integrative level: the aim is not to achieve merely host-plant resistance but agroecosystem resistance. Clearly, insect management does not exist in a vacuum: to optimize the role of cover crops in a farming system, effects on soil fertility, weeds, diseases, and plant-parasitic nematodes must be considered.

Many questions remain on how to manage cover crops to minimize problems with arthropod pests. One of the first issues to address is definitional. One definition suggested for the term "weed" is "a plant out of place." An analogous definition might serve for "arthropod pest"-"an arthropod out of place." In fact, some "pests" can actually be beneficial in some contexts, because they may attack and suppress other pests or serve as prey of beneficial arthropods. For example, flower thrips (Frunkliniella spp.) can damage various vegetable crops but are key predators of spider mites (Acari: Tetranychidae) (Gonzalez et al., 1982) and are themselves important alternative prey of various predators (Bugg et al., 1991; Gonzalez et al., 1982). In any event, potential pests are not necessarily problems, so long as they are avoided during periods when cash crops are susceptible to their attack. These "windows of vulnerability" may be wide or narrow, depending on the nature of the crop-pest relationship.

It is also important to note that many types of pest arthropods have no strong trophic associations with commonly used cover crops. This is one reason that cover crops can be useful in rotation: they can break certain pest cycles. On the other hand, if a beneficial arthropod has little association with cover crops, these crops are not likely to prove useful in enhancing the beneficial's effectiveness. In Massachusetts, Coleomegilla maculata was scarce in 10 types of cover crops, despite the presence of abundant aphids on several of these crops and despite the fact that the beetle was common in nearby corn patches (Bugg and Ellis, 1990). Since that time, I have observed numerous C. maculata imbibing the nectar of buckwheat in Pennsylvania (R.L.B., personal observation).

The initial step in managing a cover crop could be to select the appropriate plant materials for the farming system of interest. A farmer could select cover crops that harbor many beneficial insects but relatively few of which insects are likely to become pests on vegetable crops. For example, subterranean clovers harbor high densities of lady beetles (e.g.,Hippodamia convergens and Coccinella septempunctata) (Bugg et al., 1990a) but appear to be relatively poor hosts for bollworm (Heliothis zea Boddie) and tobacco budworm (Heliothis virescens Fabricius) (Snodgrass and Stadelbacher, 1989), and tarnished plant bug (Bugg et al., 1990a, 1990b). The latter is a pest of certain truck crops (e.g., lettuce, okra, strawberries) but is irrelevant for many others. Thus, cover crops that harbor high densities of this insect may not always be inappropriate. Even if a particular cover crop tends to harbor an important pest, there may be management options that can reduce the likelihood of a problem.

Cover crops can perform various functions, and cultural methods are accordingly diverse. Grown for N, cover crops are typically plowed down at or near peak flowering. Mowing or chopping may be used before incorporation or as part of a no-till operation. However, mowing is not nearly so important on most truck farms as it is with vineyard and orchard understories, where it can aid in frost protection, biomass production, and weed control. When the goal of cover cropping is to reduce leaching of soil nitrate or to supplement soil organic matter, nonleguminous species are often emphasized. An option for increasing soil organic matter is to allow maturation of cover crops in order to increase lignin content prior to plowdown. However, some cover crops can become weeds if allowed to mature and reseed (e.g., buckwheat, 'Lana' woollypod vetch Vicia villosa Roth ssp. dasycarpa Ten.). When grown to prevent erosion, cover crops may be managed by some no-till or reduced-tillage method. These varied cultural practices can have implications for arthropods.

The buildup of pests in cover crops could be reduced by: 1) use of cover crops that are nonpreferred or show antibiosis; 2) manipulating planting dates of cover crops and vegetable crops in order to "escape" the main periods of pest colonization; 3) "escape" by using early or late-maturing cover crops that are not in attractive growth stages during the main periods of pest colonization; 4) use of mixtures of cover crops that vary in their suitabilities to various pests and that harbor appropriate complexes of natural enemies, so that no single pest becomes extremely abundant; and 5) preemptive mowing or tillage when pests are mainly in nondispersive and vulnerable developmental stages (typically egg, early instars, or pupa).

The key to managing movement of vagile pests [e.g., aphids, thrips, Lygus spp., stink bugs (Pentatomidae), Norwegian plant bug (Calocoris norvegicus Gmelin)] may be maintaining the cover crop as a sink for pests. This might be accomplished by: 1) cover crops that are more attractive than the associated vegetable crops when the latter are vulnerable, including indeterminate cover crops that remain attractive to pests for long periods; 2) mixtures of early and late-maturing cover crops that continually arrest pests by providing a seasonal sequence of attractive host plants; 3) mowing high and irrigating to "rejuvenate" a maturing cover crop; and 4) mowing or tilling alternate strips to 
maintain suitable habitat. Barriers like roads and ditches can also reduce between-field movement of Lygus (Schaber et al., 1990).

Clearly, some of the suggested tactics for managing buildup or movement of pests are mutually exclusive; others are compatible. As suggested above, mowing at the proper height and time that is followed by irrigation can postpone maturation and lead to regrowth of many cover crops. If regrowth is desired, mowing should precede full flower, and the mower should be set relatively high for vetches and most grasses $(\approx 25$ to $30 \mathrm{~cm})$ so as to preserve vegetative buds. High mowing may not be feasible with flail mowers.

Cover crops may require special attention if they are to serve as field insectaries that support high densities of beneficial insects. During periods when pests are scarce, supplementary resources such as alternate prey or hosts (or, in the case of some predators, pollen) might be expected to be particularly important to beneficial arthropods. If supplied at the wrong time, however, supplementary resources may divert natural enemies from the pests of interest. By contrast, complementary resources such as nectar or honeydew might be expected to be desirable whenever beneficial insects are active. Thus, cover crops that provide supplementary and complementary foods may require different management. As suggested earlier, a complicating factor is that many cover crops provide both.

As with Lygus spp., mowing prompts dispersal of many predatory insects (Rakickas and Watson, 1974), and tillage would probably do the same. Mowing reduces the ability of cover crops to support certain beneficial arthropods (Harris and Phillips, 1986). There is little published evidence that swaths of mown alfalfa left in a field improve the retention, survival, or resurgence of populations of beneficial insects (Harper et al., 1990), although dead mulches can provide an important habitat for certain spiders in vegetable gardens (Riechert and Bishop, 1990). Use of sickle-bar mowers appears a gentler option than flail or rotary mowing, but is not always feasible (Bugg and Ellis, 1990). Setting flail or rotary mowers at greater heights might permit better survival of beneficial insects. Ability to adjust flail mowers may be limited. I found no published comparative data on the effects of different mowing techniques on survival of insects.

No-tillage approaches may conserve beneficial insects better than conventional tillage (House and Alzugaray, 1989). Many predatory wasps are ground nesting, and tillage would probably interfere with ongoing reproduction. On the other hand, such wasps often reside in disturbed areas, and superficial tillage could make available new potential nesting sites (Bugg and Ellis, 1990).

Timing of mowing or tillage may be important and could be adjusted to allow maturation or dispersal of beneficial insects (Bugg and Ellis, 1990). Remnant strips of cover crops in occasional beds or along irrigation lines could provide habitat to beneficial insects (Bugg et al., 1991).

Cover cropping may have impacts on beneficial and pest arthropods, and there is much interest among farmers in perfecting cultural and biological controls. Arthropod population dynamics are chaotic, in the sense that slight differences in initial conditions can lead to unpredictably large differences in outcome (Gleick, 1987). Much remains to be learned about how cover cropping may influence these dynamics.

\section{Literature Cited}

Altieri, M.A. and D.K. Letourneau. 1982. Vegetation management and biological control in agroecosystems. Crop Protection 1:405430.

Andow, D.A. 1988. Management of weeds for insect manipulation in agroecosystems, p. 265-301. In: M.A. Altieri and M. Liebman (eds.). Weed management in agroecosystems: Ecological approaches. CRC, Boca Raton, Fla.

Andow, D.A., A.G. Nicholson, H.C. Wien, and H.R. Willson. 1986. Insect populations on cabbage grown with living mulches. Environ. Entomol. 15: 293-299.

Bisabri-Ershadi, B. and L.D. Ehler. 1981. Natural biological control of western yellow-striped armyworm, Spodoptera praefica (Grote), in hay alfalfa in northern California. Hilgardia 49(3):1-23.

Bugg, R.L. and R.T. Ellis. 1990. Insects associated with cover crops in
Massachusetts. Biol. Agr. and Hort. 7:47-68.

Bugg, R.L. and L.T. Wilson. 1989. Ammi visnaga (L.) Lamark (Apiaceae): Associated beneficial insects and implications for biological control, with emphasis on the bell-pepper agroecosystem. Biol. Agr. Hort. 6: 107-114.

Bugg, R.L., L.E. Ehler, and L.T. Wilson. 1987. Effect of common knotweed (Polygonum aviculare) on abundance and efficiency of insect predators of crop pests. Hilgardia 55(7):1-53.

Bugg, R.L., R.T. Ellis, and R.W. Carlson. 1989. Ichneumonidae (Hymenoptera) using extra floral nectar of faba bean (Vicia faba L., Fabaceae) in Massachusetts. Biol. Agr. and Hort. 6:107-114.

Bugg, R.L., S.C. Phatak, and J.D. Dutcher. 1990a. Insects associated with cool-season cover crops in southern Georgia: implications for pest control in the truck-farm and pecan agroecosystems. Biol. Agr. and Hort. 7:17-45.

Bugg, R.L., F.L. Wäckers, K.E. Brunson, S.C. Phatak, and J.D. Dutcher. 1990b. Tarnished plant bug (Hemiptera: Miridae), on selected cool-season leguminous cover crops. J. Entomol. Sci. 25:463-474

Bugg, R.L., F.L. Wäckers, K.E. Brunson, J.D. Dutcher, and S.C. Phatak. 1991. Cool-season cover crops relay intercropped with cantaloupe: influence on a generalist predator, Geocoris punctipes (Say) (Hemiptera: Lygaeidae). J. Econ. Entomol. 84:408-416.

Cleary, T. (Translator). 1986. The Taoist I Ching. Shambhala. Boston.

Davidson, R.H., and W.F. Lyon. 1987. Insect pests of farm, garden, and orchard. 8th ed. Wiley, New York.

Ehler, L.E. and J.C. Miller. 1978. Biological control in temporary agroecosystems. Entomophaga 23:207-212.

Fleischer, S.J. and M.J. Gaylor. 1987. Seasonal abundance of Lygus lineolaris (Heteroptera: Miridae) and selected predators in early season uncultivated hosts: implications for managing movement into cotton. Environ. Entomol. 16:379-389.

Gleick, J. 1987. Chaos: Making a new science. Penguin, New York.

Gonzalez, D., B.R. Patterson, T.F. Leigh, and L.T. Wilson. 1982. Mites: a primary food source for two predators in San Joaquin Valley cotton. Calif. Agr. 36(2.3):18-20.

Groden, E., F. Drummond, R.A. Casagrande, and D.L. Haynes. 1990. Coleomegilla maculata (Coleoptera: Coccinellidae): its predation upon the Colorado potato beetle (Coleoptera: Chrysomelidae) and its incidence in potatoes and surrounding crops. J. Econ. Entomol. 83:1306-1315

Hagen, K.S. 1974. The significance of predaceous Coccinellidae in biological and integrated control of insects. Entomophaga 7:2544.

Harper, A.M., B.D. Schaber, T.P. Story, and T. Entz. 1990. Effect of swathing and clear-cutting alfalfa on insect populations in southern Alberta. J. Econ. Entomol. 83:2050-2057.

Harris, V.E. and J.R. Phillips. 1986. The effect of mowing springweed hosts of Heliothis spp. on predatory arthropods. J. Agr. Entomol. 3:77-86.

Hirose, Y. 1966. Parasitic Hymenoptera visiting the flowers of carrot planted in the truck crop field. Sci. Bul. Faculty Agr., Kyushu Univ., Ser. 2,22(3):217-223.

Hodek, I., Z. Ruzicka, and M. Hodkova. 1978. Pollinivorie et aphidophagie chez Coleomegilla maculata lengi. Ann. Zoology and Ecol. Animals 10:453-459.

Hokkanen, H.M.T. 1991. Trap cropping in pest management. Annu. Rev. Entomol. 36:119-138.

House, G.J., and M.D.R. Alzugaray. 1989. Influence of cover cropping and no-tillage practices on community composition of soil arthropods in a North Carolina agroecosystem. Environ. Entomol. 18:302-307.

Jansson, R.K. and S.H. Lecrone. 1991. Effects of summer cover crop management on wireworm (Coleoptera: Elateridae) abundance and damage to potato. J. Econ. Entomol. 84:581-586.

Kennedy, G.G. and D.C. Margolies. 1985. Mobile arthropod pests: management in diversified agroecosystems. Bul. Entomol. Soc. Amer. 31(3):21-27.

Maingay, H., R.L. Bugg, R.W. Carlson, and N.A. Davidson. 1991. Predatory and parasitic wasps (Hymenoptera) feeding at flowers of sweet fennel (Foeniculum vulgare Miller var. dulce Battandier \& Trabut, Apiaceae) and spearmint (Mentha spicata L., Lamiaceae) in Massachusetts. Biol. Agr. and Hort. 7:363-383. 
Marsh, P.M. 1979. Family Aphidiidae, p. 295-313. In: K.V. Krombein, P.D. Hurd, D.R. Smith, and B.D. Burks (eds.). Catalog of Hymenoptera in America north of Mexico. Smithsonian Press, Washington, D.C., 3v., xvi, xvi, xxx.

Meagher, R.L. Jr., and J.R. Meyer. 1990. Influence of ground cover and herbicide treatments on Tetranychus urticae populations in peach orchards. Experimental and Applied Acarology 9:149-158.

Metcalf, C.L., W.P. Flint, and R.L. Metcalf. 1962. Destructive and useful Insects: Their habits and control. 4th ed. McGraw-Hill, New York.

Rakickas R.J. and T.F. Watson. 1974. Population trends of Lygus spp. and selected predators in strip-cut alfalfa. Environ. Entomol. 3:781784.

Riechert, S.E. and L. Bishop. 1990. Prey control by an assemblage of generalist predators: spiders in garden test systems. Ecology
71:1441-1450.

Schaber, B.D., A.M. Harper, and T. Entz. 1990. Effect of swathing alfalfa for hay on insect dispersal. J. Econ. Entomol. 83:24272433.

Smith, B.C. 1960. A technique for rearing coccinellid beetles on dry foods, and influence ofvarious pollens on the development of Coleomegilla maculata lengi Timb. (Coleptera: Coccinellidae) Can. J. Zoology 38:1047-1049.

Snodgrass, G.L. and E.A. Stadelbacher. 1989. Effect of different grass and legume combinations on spider (Araneae) and ground beetle (Coleoptera: Carabidae) populations in roadside habitats in the Mississippi Delta. Environ. Entomol. 18:575-581.

Tamaki, G. 1981. Biological control of potato pests, p. 178-192. In: J.H. Lashomb and R. Casagrande (eds.). Advances in potato pest management. Hutchinson Ross, Stroudsberg, Pa. 